\title{
The Possible Involvement of Epstein -Barr virus In the Etiology of Leukemia
}

\author{
Haitham E Elawad ${ }^{1 *}$, Shamsoun K Kafi ${ }^{2}$, Ismail Abd Elrahman², Salaheldein G Elzaki ${ }^{3}$, Abuelgasim Eljaili $^{1}$, Mohammed E Ornasir ${ }^{1}$ and \\ Mohammed Y Elamir ${ }^{1}$
}

${ }^{1}$ Department of Microbiology, Medical Laboratories Sciences, Omdurman Islamic University, Omdurman, Sudan

${ }^{2}$ National Ribat University College of Medical Laboratories Sciences, Khartoum, Sudan

${ }^{3}$ Radiation and Isotope Centre Khartoum (RICK) Khartoum, Sudan

\begin{abstract}
Background: Although considerable brainstorm has been known into Epstein-Barr virus EBV as an important etiologic factor in various tumors, virtually little is known about the relationship between EBV genes and leukemia The actual cause of Leukemia, which is a serious cancer in Sudan, is still under scrutiny. Controversial hypotheses were proposed suggesting the role of physical as well as chemical and even biological factors as being responsible for Leukemia incidents. We hypothesized that EBV could be involved in the etiology of leukemia. We describe here the results of our attempt to find a possible link between leukemia and EBV.

Methods: Real-time Polymerase Chain Reaction assay (q-PCR) has recently been used widely for detection of Cell-free EBVDNA in the plasma of patients with leukemia. To determine the possible correlation between plasma cell-free EBV DNA levels and the leukemia, we studied the plasma EBV DNA levels in patients with leukemia that were presented at Radiation and Isotope Centre Khartoum (RICK), Sudan during therapy. The concentrations of plasma cell-free EBV DNA of 128 leukemic patients, 17 patients with EBV-associated lymphoid malignancies during the course of therapy Burkitt's lymphoma, Hodgkin's disease, Nasopharyngeal carcinoma (NPC) as control positive and 15 healthy controls were determined by using the ( $q-P C R)$ assay with the PrimerDesign ${ }^{\mathrm{TM}}$ genesig quantification kit.

Results: The results revealed that EBV DNA was detectable in a wide range of leukemia patients. Plasma EBV DNA was detected in 33/88 Acute lymphoblastic leukemia (ALL) patients 28/40 Chronic myelogenous leukemia (CML),15/17 patients with EBV-associated lymphoid malignancies, but not in any of 15 healthy control subjects. The median concentration of EBV DNA in leukemia and healthy control groups was 6561.00 and $0.00 \mathrm{copies} / \mathrm{ml}$, respectively.

Conclusion: Our findings provided evidence of the involvement of EBV in patients with leukemia. The results suggested that EBV DNA genome encoding the non-glycosylated membrane protein BNRF1 pl43 was observed in a significant proportion of patients with ALL. However, we could not exclude a correlation between these viral infections and later leukemogenesis in childhood ALL in Sudan.
\end{abstract}

Keywords: EBV; Real-time quantitative PCR; Leukemia; Diagnosis; BNRF1

\section{Abbreviations}

EBV: Epstein - Barr Virus; (q-PCR): Real-time Polymerase Chain Reaction assay; RICK: Radiation and Isotope Centre Khartoum; BL: Burkitt's Lymphoma; HD: Hodgkin's Disease; NPC: Nasopharyngeal Carcinoma; ALL: Acute Lymphoblastic Leukemia; CML: Chronic Myelogenous Leukemia; CR: Complete Remission

\section{Introduction}

Leukemia is a cancer of the blood or bone marrow characterized by an abnormal increase of blood cells, usually leukocytes (white blood cells). Leukemia is a broad term covering a spectrum of diseases. In turn, it is part of, the even, broader group of diseases called hematological neoplasms [1]. EBV is a herpesvirus that infects and establishes a persistent infection in humans. Following a primary infection in healthy individuals, EBV infects and immortalizes B lymphocytes, which is followed by a lifelong viral latency $[2,3]$. Proliferation of EBV infected $\mathrm{B}$-cells is prevented and controlled by an adequate T-cell dependent specific immune response. However, strong reduction in the numbers of EBV-specific T lymphocytes may result in reactivation of the virus and, ultimately, the development of lymphoproliferative disease (EBVLPD) [4]. The EBV BZLF1-encoded replication activator (ZEBRA) is a key mediator of reactivation from latency to the viral productive cycle. Among the EBV transactivators, the ZEBRA protein plays a crucial role in switching the virus from a latent to a productive mode [5]. This virus has been implicated in the development of a number of lymphoid malignancies. Burkitt's lymphoma was the first neoplasm found to be related to EBV, with a nearly $100 \%$ association in endemic areas, but less than $20 \%$ in low-incidence areas [6]. No single known cause for all of the different types of leukemia exists. The known causes, which are not generally factors within the control of the average person, account for relatively few cases [7]. Several studies have reported the presence of EBV DNA in the peripheral blood of patients with ALL $[8,9]$. Most

*Corresponding author: Haitham Eltigani Mohammed Elawad, Omdurman Islamic University, Omdurman, Sudan, Faculty of Medical Laboratory Sciences, Khartoum, Sudan, Tel: +249915312021; E-mail: Haithamtig@outlook.com

Received October 16, 2014; Accepted December 22, 2014; Published December 24, 2014

Citation: Elawad HE, Kafi SK, Elrahman IA, Elzaki SG, Eljaili A, et al. (2014) The Possible Involvement of Epstein -Barr virus In the Etiology of Leukemia. J Med Microb Diagn 4: 174. doi:10.4172/21610703.1000174

Copyright: @ 2014 Elawad HE, et al. This is an open-access article distributed under the terms of the Creative Commons Attribution License, which permits unrestricted use, distribution, and reproduction in any medium, provided the original author and source are credited. 
used either peripheral blood mononuclear cells or B-lymphocytes for EBV detection and showed increased levels of EBV DNA. Recently, much interest has been focused on the detection of tumourderived DNA in the cell-free fractions, namely plasma or serum, of blood samples [10-12]. However, few literature points towards the controversial role of EBV in childhood leukemia. Employing sensitive and specific molecular tools like Real time PCR assay, EBV LMP1 gene transcriptional activity was observed in a significant proportion of patients with acute lymphoblastic leukemia. EBV infection in patients with lymphoid leukemia may be a factor involved in the high incidence of paediatric leukemia in the Sudan [8]. A study upon Finnish and Icelandic maternity cohorts to verify/falsify the association of maternal EBV infection with an increased risk of ALL in the offspring, (during 1983 to 2006 in Finland and 1997 to 2005 in Iceland), was carried out. It was concluded that there was no evidence of increased risk of ALL associated to EBV and the data argued against a role of EBV in ALL [13]. On the other hand, in 2003, Dr. Matti Lehtinen from National Public Health Institute, Oulu, Finland, and colleagues identified a link between maternal EBV reactivation and the development of ALL in offspring. They found some further confirmation to their findings, suggesting an association between maternal EBV infection and risk of Leukemia in the offspring, especially infants below 1 year of age [9]. Masao O, Takako et al. studied the etiology of cytomegalovirus (CMV), human herpesvirus-6 (HHV-6), and EBV reactivation and the potential for complications following cytotoxic chemotherapy in the absence of allogeneic transplantation. Their findings demonstrated that subclinical reactivation of CMV, HHV-6, and EBV were common in Adult T Cell Leukemia (ATL) patients receiving chemotherapy [14]. In fact, EBV does not directly cause a specific disease of its own, as is the case of other pathogens, but it plays a role in the etiology of several diseases, as for example cancer, rheumatoid, and a co-factor to several autoimmune diseases, to name but a few. This characteristic, logically, leads to the presumption that it is involved in leukemia incidents. A causative link between EBV and leukemia, a disease with a distinctly high incidence in Sudan, has been widely investigated. However, no full-length analysis of any substrain of EBV in this area has been reported.

\section{Objectives}

In the current study, we sought evidence whether EBV is associated with the development of childhood leukemia in the Sudan.

\section{Materials and Methods}

\section{Enrollment of patients}

Patients with leukemia that were presented at Radiation and Isotope Centre Khartoum (RICK) Sudan have been studied for evidence of EBV infection. The patient's Consent and approval were requested by the (RICK) Ethics authorities to obtain clinical materials for research purposes. The patients were, beforehand diagnosed using several diagnostic parameters, including cell morphology and flow cytometry.

\section{Sample collection}

Plasma samples taken from 160 of treated leukemia patients, of different cohorts were collected upon their consent.

\section{Extraction of EBV DNA}

Cell-free EBV DNA from all plasma samples was extracted by using a Purification of DNA by phenol extraction and ethanol precipitation protocol (Oxford practical approach series) according to the user manual and kept at $-20^{\circ} \mathrm{C}$ until used. Briefly, a $200 \mu \mathrm{l}$ plasma sample was added to equal volume phenol, and add an equal amount of 24:1 $(\mathrm{v} / \mathrm{v})$ chloroform-isoamyl alcohol, centrifuged at $8000 \mathrm{rpm}$ for $1 \mathrm{~min}$ to separate the aqueous phase (supplemented with $20 \mu$ l proteinase $\mathrm{K}$ ) in a $1.5 \mathrm{ml}$ microcentrifuge tube, mixed immediately and incubated at $65^{\circ} \mathrm{C}$ for 2 hours. In order to precipitate the DNA, $20 \mu \mathrm{l}$ of $3 \mathrm{M}$ sodium acetate, $\mathrm{pH} 5.5$ and $300 \mu \mathrm{l}$ of absolute ethanol were added, followed by Incubation at $-20^{\circ} \mathrm{C}$ overnight. The precipitated DNA was recovered by centrifugation at $10000 \mathrm{rpm}$ for $15 \mathrm{~min}$. Then the DNA was washed twice with $70 \%(\mathrm{v} / \mathrm{v})$ ethanol to remove excess salt from the pellet. Finally, the DNA was resuspended in sterile TE, $\mathrm{pH}$ 8.0, and stored at $-20^{\circ} \mathrm{C}$. The final volume of DNA obtained from each sample was $100 \mu$ l.

\section{Detection of Plasma Cell-free EBV DNA}

The PrimerDesign ${ }^{\text {tx }}$ genesig Kit for Human Herpes Virus 4 EBV Genomes is designed for the in vitro quantification of EBV genomes. The target sequence within the BNRF1 gene has previously been shown to be a good genetic marker for EBV in other clinical real time PCR based studies [15-23]. The kit is designed to have the broadest detection profile possible whilst remaining specific to the EBV genome. The primers and probe sequences in this kit have $100 \%$ homology with a broad range of clinically relevant reference sequences based on a comprehensive bioinformatics analysis.

\section{Quantitative EBV-specific PCR}

DNA from plasma was amplified using Taqman PCR primers selective for the EBV DNA genome encoding the non-glycosylated membrane protein BNRF1 pl43. BNRF1 pl43 was used as the target gene in this assay. PCR amplification and detection was performed with (Swift Spectrum 48 Thermal Cycler) detection system (ESCO). In the PCR reaction, a fluorigenic EBV/p143-specific probe was added with a FAM reported molecule attached to the $59^{\text {th }}$ end and a TAMRA quencher linked at the $39^{\text {th }}$ end to detect amplified DNA. Real time measurements were taken and a threshold cycle $(\mathrm{Ct})$ value was calculated for each sample by determining the point at which the fluorescence exceeded a threshold limit of 50. Each run contained a negative control (no template or EBV negative DNA), a positive control (a known amount of EBV copies). The standard curve was created automatically by the (ESCO) (Swift Spectrum 48 Thermal Cycler) Detection System Software, by plotting the Ct values against each standard of known concentration.

\section{Statistical Analysis}

Data management was done by using the Statistical Package for Social Sciences (SPSS version 11.5; SPSS Inc, Chicago, IL). SPSS was used for analysis and to perform Fisher exact test for statistical significance ( $P$ value). The 95\% confidence level was used. Comparison of plasma EBV DNA concentrations between controls and patients were performed using the Mann-Whitney $\mathrm{U}$-test. $\mathrm{P}$ value $<0.05$ was considered statistically significant.

\section{Results}

\section{Development of real-time quantitative PCR}

To determine the dynamic range of real-time quantitative PCR, serial dilutions of DNA were made and subjected to analysis by the EBV real-time quantitative PCR system. Figure 1 shows the amplification curve result obtained using the BNRF1region PCR system. The system was sensitive enough to detect 5 copies of EBV DNA. Figure 2 shows a plot of the threshold cycle (CT) of the EBV BNRF1 region PCR which 


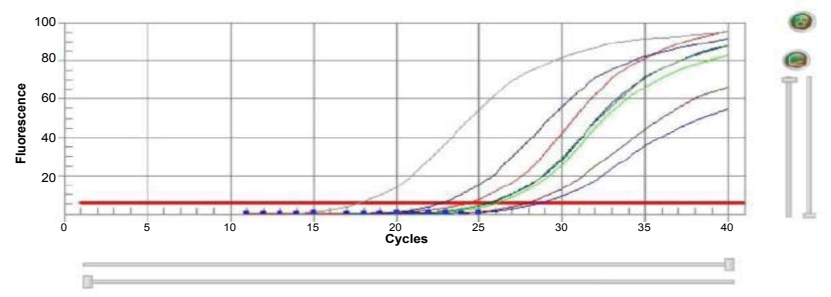

Figure 1: The q-PCR amplification plot of standard control of EBV DNA, the point that the fluorescence signal increased above baseline is the threshold cycle (CT). Each plot corresponds to a particular input target quantity marked by a corresponding symbol. The $X$ axis denotes the cycle number of a quantitative $\mathrm{PCR}$ reaction. The $\mathrm{Y}$ axis denotes the fluorescence intensity.

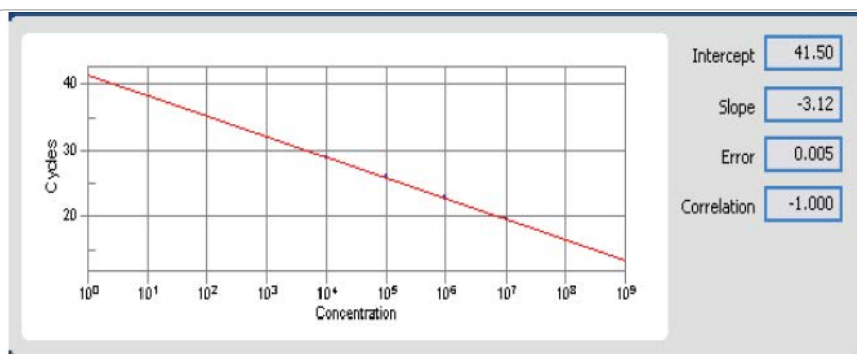

Figure 2: Plot of the threshold cycle (CT) against the input target quantity (common log scale). The input target quantity was expressed as copies of EBV DNA. The correlation coefficient is 0.994 .

plotted on a common logarithmic scale. The threshold cycle (CT) was set at 10 serial dilutions (SDs) above the mean baseline fluorescence calculated from cycles 1-15 and was proportional to the starting target copy number (logarithmic scale) used for amplification. The linearity of the graph demonstrates the large dynamic range and the accuracy of real-time quantitative PCR.

\section{Detection of plasma EBV DNA in leukemic groups and controls}

EBV DNA genome encoding the non-glycosylated membrane protein BNRF1 pl43 was successfully detected by real-time PCR in 61 (47.6\%) of the 128 leukemia cases, 15 (88.2\%) of the 17 patients with EBV-associated lymphoid malignancies the control positive with the mean level of $19683 \pm 2187$ copies $/ \mathrm{ml}$, and in none of the 15 healthy controls with the mean level of 0 copies/ $\mathrm{ml}(P$

$<0001)$. The mean level of plasma cell-free EBV DNA in leukemic patients was significantly higher than healthy controls at $\mathrm{p}<0.001$. The median concentration of plasma cell-free EBV DNA in leukemia groups was 6561.00 copies $/ \mathrm{ml}$ whereas in healthy controls group was 0.0 copies $/ \mathrm{ml}$. The plasma cell-free EBV-DNA levels in healthy controls and leukemic Patients are summarized in Table 1. In terms of gender; the majority of patients were male $80(62.5 \%)$ while $50(37.5 \%)$ were females. The distribution of EBV BNRF1 pl43 in different leukemic lymphomas subtypes is as follows: 33 (37.5\%) of 88 ALL and 28 (70\%) of $40 \mathrm{CML}$ (Figure 3$)$. This was significantly higher $(P<0.01$; chisquare test) compared with the incidence in the control group (0 of 15 individuals; 0\%). When we compared plasma EBV DNA levels in these patients, we found that the median titers were significantly higher $(P<0.001$; Mann-Whitney rank sum test $)$ in patients with leukemia (6561.00 copies/ ml). In this study, patients with $\mathrm{EBV}^{+}$leukemic lymphomas in different age ranges were as follows: 23 (17.7\%) of 75 for age range $1-9$ years, $19(14.6 \%)$ of 32 for $10-19$ years, and $2(1.5 \%)$ of 2 for $20-29$ years, 6 (4.6\%) of 8 for 30-39 years, 4 (3.1\%) of 4 for $40-39$ years, 7 (5.4\%) of 9 for 50-80 years. Eighty eight pediatric patients that underwent chemotherapy treatment at RICK comprised the ALL study group. The plasma cell-free EBV DNA was successfully detected in 12 (31.5\%) of 38 complete remission (CR (1), $12(42.8 \%)$ of 28 complete remission (CR (2), 5(38.4\%) of 13 complete remission (CR(3) and 4 (30.7\%) of 13 follow-up (Figure 4).

\section{Discussion}

A defining feature of herpes viruses is their ability to maintain a latent infection with the virus genome retained in host cells without production of infectious virions. EBV targets B lymphocytes through the $\mathrm{CD} 21$ receptor and establishes a latent infection both in vivo and in vitro [23]. In recent years some convincing leads have been obtained on a causal relationship between EBV and a variety of childhood leukemia. EBV can be considered as the prototype of oncogenic viruses that behave as direct transforming agents. In fact, in classical EBV-associated tumors, the virus genome is present in virtually all neoplastic cells, which show the expression of viral RNAs and proteins that variously contribute to the induction of the transformed phenotype. On the basis of these features and of the strict association with distinct tumor types, EBV has been classified as a group I carcinogen. The presence of this herpesvirus has been variably detected in a broad spectrum of other tumors for which a causal role of EBV seems unlikely. These tumors include also chronic lymphocytic leukemia, yet the authors reviewed data suggesting a possible role of EBV as a direct or microenvironmental progression factor in a fraction of CLL [24]. Leukemia, like other cancers, results from somatic mutations in the DNA. Certain mutations produce leukemia by activating oncogenes or deactivating tumor suppressor genes, and thereby disrupting the regulation of cell death, differentiation or division. These mutations may occur spontaneously or as a result of exposure to radiation or carcinogenic substances, and are likely to be influenced by genetic factors [25]. Among adults, the known causes are natural and artificial ionizing radiation, a few viruses such as Human T-lymphotropic virus, Epstein-Bar virus, Cytomegalovirus and some chemicals, notably benzene and alkylating chemotherapy agents for previous malignancies [26].The results of our study revealed a relative correlation between plasma cell-free EBV DNA levels and the leukemia in Sudanese patients. The results were correlated with those of, Ahmed et al. Matti et al. Lu et al. and Sehgal et al. $[8,9,27,28]$ but not Tedeschi et al. [13]. Ahmed et al. observed that EBV LMP1 gene transcriptional activity was in a significant proportion of Sudanese patients with acute lymphoblastic leukemia. They suggested that EBV may be a factor involved in the high incidence of paediatric leukemia in the Sudan. Matti et al. in Finland identified a link between maternal EBV reactivation and the development of ALL in offspring. The paucity of such important information prompted us to perform a serial analysis of circulating EBV DNA levels at multiple time points during treatment using real-time quantitative PCR assay.

\begin{tabular}{|c|c|c|c|c|c|c|c|}
\hline \multirow{2}{*}{$\begin{array}{c}\text { Leukemic and } \\
\text { control groups }\end{array}$} & \multicolumn{6}{|c|}{ EBV viral load in terms of copies/cell } \\
\cline { 2 - 9 } & 0 & 2187 & 6561 & 19683 & 59049 & 177147 & $\begin{array}{c}\text { Total of } \\
\text { patients }\end{array}$ \\
\hline ALL & 55 & 9 & 10 & 6 & 7 & 1 & 88 \\
\hline CML & 12 & 1 & 8 & 12 & 7 & 0 & 40 \\
\hline $\begin{array}{c}\text { Positive control } \\
\text { (NPC,BL,HL) }\end{array}$ & 2 & 0 & 0 & 2 & 10 & 3 & 17 \\
\hline Negative control & 15 & 0 & 0 & 0 & 0 & 0 & 15 \\
\hline Total of copies & 48 & 10 & 18 & 20 & 24 & 4 & 160 \\
\hline
\end{tabular}

$\mathrm{ALL}=$ Acute lymphoblastic leukemia, $\mathrm{CML}=$ Chronic myelogenous leukemia NPC=Nasopharyngeal carcinoma, BL=Burkitt's lymphoma, $\mathrm{HL}=$ Hodgkin's disease Table 1: The plasma cell-free EBV-DNA levels in healthy controls and leukemic Patients 


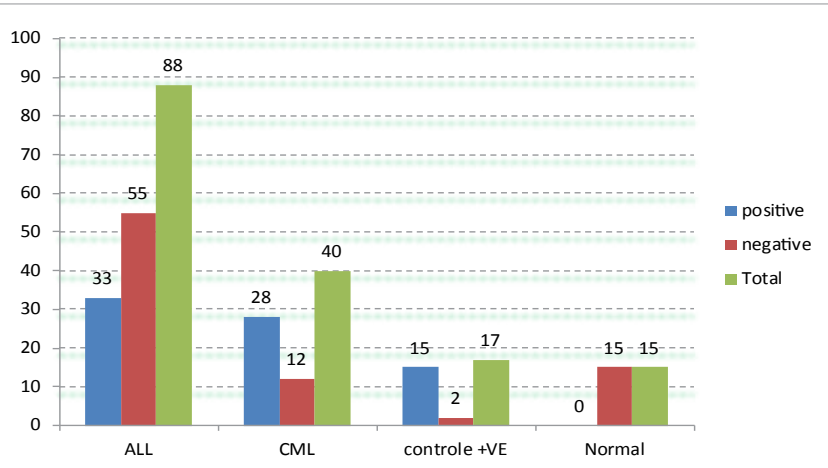

Figure 3: Description of EBV BNRF1 in Different Leukemic Lymphomas Subtypes

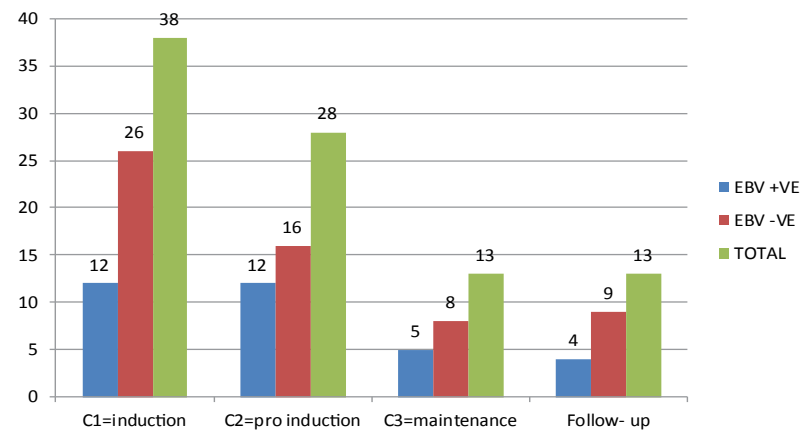

Abbreviations: $(C R(1)=$ complete remission (induction), $(C R \quad(2)=$ complete remission (pro-induction ), (CR (3)= complete remission (maintenance) Figure 4: Description of EBV BNRF1 in Different treatment stages

This report is supported by our findings, and the incidence of EBV in pediatric leukemia in the Sudan might be higher than this because we only detected BNRF1 gene, which could probably detect the majority of cases associated with EBV. Our samples were taken from patients receiving treatment, so the EBV viral load levels might decline to 0 copies/cell after completion of radiotherapy even in cases of cancers already known that the EBV is the causative agent like NPC $[29,30]$. Furthermore, Kenny et al. reported that all patients who responded to therapy demonstrated a significant reduction of plasma EBV DNA to low or undetectable levels, whereas in patients with ineffective therapy, disease progression was associated with a rapid increase in plasma EBV DNA levels [31].The disagreement might be due to the differences in the source of the cell-free EBV DNA and the differences in the type of samples that selected for the individual studies.

\section{Conclusion}

In conclusion, the results obtained suggest that plasma cell-free EBV DNA is a highly specific marker for a screening and diagnosis of EBV-associated diseases. The feasibility of using quantitative analysis to determine the possible relationship between the clinical outcome and the level of plasma cell-free EBV DNA are warranted features in childhood ALL. Further investigation on the link between maternal EBV reactivation and the development of ALL in offspring. Needs to be explored. Nor latent infection nor congenital infection cannot be excluded.

\section{Ethics}

This study was approved by Sudan Medical specialization Ethics Review Board, Sudan.

\section{Acknowledgements}

The authors are very grateful to all the patients for their co-operation. This work was supported by grants from the National Ribat University College of Medical Laboratories Sciences.

\section{Authors' Contribution}

HEM carried out the study and participated in the statistical analysis and procedures. AES, MYE and MEH carried out the practical part of the study. SKK and IMO coordinated and participated in the design of the study, statistical analysis and the drafting of the manuscript. All the authors read and approved the final version.

\section{References}

1. Bacher U, Haferlach T, Schnittger S, Weiss T, Burkhard O, et al. (2010) Detection of a $t(4 ; 14)(p 16 ; q 32)$ in two cases of lymphoma showing both the immunophenotype of chronic lymphocytic leukemia. Cancer Genet Cytogenet 200: 170-174.

2. Gross TG, Steinbuch M, DeFor T, Shapiro RS, McGlave P, et al. (1999) B cell lymphoproliferative disorders following hematopoietic stem cell transplantation: risk factors, treatment and outcome. Bone Marrow Transplant 23: 251-258.

3. Micallef INM, Chhanabhai M, Gascoyne RD, Shephard JD, Fung HC, et al (1998) Lymphoproliferative disorders following allogeneic bone marrow transplantation: the Vancouver experience. Bone Marrow Transpl 22: 981-987.

4. Lucas KG, Small TN, Heller G, Dupont B, O'Reilly RJ (1996) The development of cellular immunity to Epstein-Barr virus after allogeneic bone marrow transplantation. Blood 87: 2594-2603.

5. Tedeschi R, Dillner J, Paoli PD (1996) Antibody responses to defined epitopes in the Epstein-Barr virus BZLF1-encoded transactivator protein among human immunodeficiency virus-infected patients. ClinDiagn Lab Immunol 3: 363-364.

6. Klein G (1998) EBV and B cell lymphomas. In: Herpesviruses and Immunity (ed. by P.G. Medveczky, H. Friedman, \& M. Bendinelli), 163-190. Infectious Agents and Pathogenesis. Plenum Press, New York, USA

7. Hoffbrand AV, Moss PAH, and Pettit JE (2006) Essential Haematology Blackwell, 5th ed.

8. Ahmed HG, Osman SI, Ashankyty IM (2012) Incidence of Epstein-Barr virus in pediatric leukemia in the Sudan. Clin Lymphoma Myeloma Leuk 12: 127-131.

9. Matti L, Rosamaria T, Aini B, Ögmundsdottir HM, Alessia M, Joakim, et al. ( 2006) Activation of Maternal Epstein-Barr Virus Infection and Risk of Acute Leukemia in the Offspring. American Journal of Epidemiology 165: 134-137.

10. Chen XQ, Stroun M, Magnenat JL, Nicod LP, Kurt AM, et al. (1996) Microsatellite alterations in plasma DNA of small cell lung cancer patients. Nat Med 2: 10331035.

11. Frickhofen N, Müller E, Sandherr M, Binder T, Bangerter M, et al. (1997) Rearranged Ig heavy chain DNA is detectable in cell-free blood samples of patients with B-cell neoplasia. Blood 90: 4953-4960.

12. Nawroz H, Koch W, Anker P, Stroun M, Sidransky D (1996) Microsatellite alterations in serum DNA of head and neck cancer patients. Nat Med 2: 10351037.

13. Tedeschi R, Luostarinen T, Marus A, Bzhalava D, Ogmundsdottir HM, et al (2009) No risk of maternal EBV infection for childhood leukemia. Cancer Epidemiol Biomarkers Prev 18: 2790-2792.

14. Masao O, Takako SR (2011) High Incidence of Cytomegalovirus, Human Herpesvirus-6, and Epstein-Barr Virus Reactivation in Patients Receiving Cytotoxic Chemotherapy for Adult T Cell Leukemia. Journal of Medical Virology 83:702-709.

15. Niesters HG, van Esser J, Fries E, Wolthers KC, Cornelissen J, et al. (2000) Development of a real-time quantitative assay for detection of Epstein-Barr virus. J Clin Microbiol 38: 712-715.

16. Epstein Ma, Achong Bg, Barr Ym (1964) Virus Particles In Cultured Lymphoblasts From Burkitt's Lymphoma. Lancet 1: 702-703.

17. Kieff E, Rickinson $A B$ (2001) Epstein-Barr virus and its replication. In: Knipe DM, Howley PM, Griffin DE, LambRA, Martin MA, Roizman B, et al. editor Fields virology,4th ed., Vol. 1. Philadelphia: Lippincott Williams \& Wilkins 2511-73. 
Citation: Elawad HE, Kafi SK, Elrahman IA, Elzaki SG, Eljaili A, et al. (2014) The Possible Involvement of Epstein -Barr virus In the Etiology of Leukemia. J Med Microb Diagn 4: 174. doi:10.4172/21610703.1000174

Page 5 of 5

18. Macsween KF, Crawford DH (2003) Epstein-Barr virus-recent advances. Lancet Infect Dis 3: 131-140.

19. Kobbervig C, Norback D, Kahl B (2003) Infectious mononucleosis progressing to fatal malignant lymphoma: a case report and review of the literature. Leuk Lymphoma 44: 1215-1221.

20. Chan KC, Lo YM (2002) Circulating EBV DNA as a tumor marker for nasopharyngeal carcinoma. Semin Cancer Biol 12: 489-496.

21. Boulter AW, Soltanpoor N, Swan AV, Birnbaum W, Johnson NW, et al. (1996) Risk factors associated with Epstein-Barr virus replication in oral epithelial cells of HIV-infected individuals. AIDS 10: 935-940.

22. Young LS, Murray PG (2003) Epstein-Barr virus and oncogenesis: from latent genes to tumours. Oncogene 22: 5108-5121.

23. Hopwood PA, Thomas JA, Dorothy H, Crawford (2002) Expansion in scid mice of Epstein-Barr virus-associated post-transplantation lymphoproliferative disease biopsy material. J Gen Virol 1: 173-178.

24. Dolcetti R, Carbone A (2010) Epstein-Barr virus infection and chronic lymphocytic leukemia: a possible progression factor? Infect Agent Cancer 5: 22.

25. Lesty C, Baudet S, Charlotte F (2010) A study of bone marrow neoangiogenesis in chronic lymphocytic leukemia patients. Anal Quant Cytol Histol 32: 11-23.
26. Leonard, Barry (1998) Leukemia: A Research Report. DIANE Publishing 14

27. Lu Y, Sun LR, Pang XY, Lu ZH, Sui AH (2007) [Infection status and clinical significance of Epstein-Barr virus in pediatric leukemia---a report of 35 cases] Ai Zheng 26: 54-57.

28. Sehgal S, Mujtaba S, Gupta D, Aggarwal R, Marwaha RK (2010) High incidence of Epstein Barr virus infection in childhood acute lymphocytic leukemia: a preliminary study. Indian J Pathol Microbiol 53: 63-67.

29. Shao JY, Li YH, Gao HY, Wu QL, Cui NJ, Zhang L, et al. (2004) Comparison of Plasma Epstein-Barr Virus (EBV) DNA Levels and Serum EBV Immunoglobulin A/Virus Capsid Antigen Antibody Titers in Patients with Nasopharyngeal Carcinoma. American Cancer Society 100: 1162-1170.

30. Somjin C, DanaiT, Ekapob S (2008) Quantitative Detection of PlasmaCell-free Epstein-Barr Virus DNA in Nasopharyngeal Carcinoma Patients by Real-time PCR Thi cancer j $28: 1$

31. Lei KI, Chan LY, Chan WY, Johnson PJ, Lo YM (2000) Quantitative analysis of circulating cell-free Epstein-Barr virus (EBV) DNA levels in patients with EBVassociated lymphoid malignancies. Br J Haematol 111: 239-246. 